\title{
PERANCANGAN PROGRAM LOGIKA KONTROL PADA PROSES PEMBUATAN ROTI
}

\author{
Rini Lutfiyani' ${ }^{1)}$,Hesky S.Kolibu' ${ }^{1)}$, As'Ari' ${ }^{1)}$ \\ 1)Program Studi Fisika FMIPA UNSRAT, Manado \\ e-mail: lutfiyanirini@yahoo.com; Heskystevy@yahoo.com; as.ari2222@yahoo.co.id
}

\begin{abstract}
ABSTRAK
Telah di rancang sistem kontrol pada proses pembuatan Roti. Pengontrolan fungsi kerja alat dilakukan melalui Monitoring dengan Komputer yang di program dengan menggunakan Bahasa Pemrograman Ladder Diagram untuk mengatur proses kerja Alat. Dalam penelitian ini untuk mengetahui input sama dengan output arus listrik maka di uji menggunakan mulitester untuk bisa menghitung tegangan yang akan di rangkai sirkuit lampu Flip-flop berdasarkan proses pembuatan roti. Begitupun diaplikasikan seperti pada mixer roti sebagai pengadon.
\end{abstract}

Kata Kunci : PLC (programmable Logic Control), Proses Pembuatan Roti.

\section{DESIGN PROGRAM LOGIC CONTROL IN PROCESS OF BREAD}

\begin{abstract}
A designed Has been done to control system in the process of making bread. Controlling function sperformed by monitoring tools work with he computer program using Programming Languages Ladder Diagram Tool to manage work processes. In this study to determine the input equals'output electric current then test educing multitester to be able to calculate the voltage to bein the chain lights Flip-flop circuit based on the process of making bread. Like wise applied as in the bread mixer as dough maker.
\end{abstract}

Keywords: PLC (programmable Logic Control), Process of bread.

\section{PENDAHULUAN}

Pengembangan produk industri rumah tangga pada masyarakat perlu ditingkatkan untuk pembaruan teknologi sebagai inovasi bidang industri bisnis. Dalam hal ini, produk usaha industri rumah tangga yang potensi terutama Manado adalah produk makanan yang menjadi ciri khas daerah ini. Oleh karena itu, berbagai produk olahan dari makanan ringan sampai makan berat seharusnya tersedia disini.

Industri rumah tangga Roti sendiri sejak dulu dilakukan secara manual atau menggunakan tangan. Hal ini dari segi waktu tidak efisien, memerlukan tenaga besar serta hasil industri yang tidak maksimal. Sekarang ini proses pembuatan roti dengan menggunakan mesin sehingga hasil yang di dapatkan lebih meningkat di bandingkan dengan pembuatan Roti secara manual.
Pengontrolan pada mixer dalam
proses pembuatan adonan akan menghasilkan kualitas produk yang baik secara kontinu. Pengontrolan pada mixer dalam bentuk pengaturan waktu (timer) yang terdapat dalam PLC (program Logika Kontrol).

Perkembangan teknologi komputer baik hardware maupun software terus berkembang seiring perkembangan teknologi eletronika yang semakin maju, demikian juga teknologi kontrol yang mengalami banyak kemajuan dari kontrol konvensional ke kontrol otomatik sampai ke kontrol cerdas ( Ali, 2004) .

Penelitian ini menggunakan sistem kendali Program logika Kontrol yang memiliki 3 fungsi penghubung yaitu input arus listrik yang masuk, Kontrol prosesor PLC dan Komputer sebagai pengontrol waktu dapat dimonitoring berbentuk 
bahasa program ladder diagram dan output pada motor listrik yang terhubung dengan proses pembuatan Roti.

\section{PLC (Programmable logic control)}

PLC adalah perangkat untuk melaksanakan fungsi kendali dan monitor yang dapat di program. Selain dikenal sebagai PLC dibeberapa tempat perangkat ini disebut Programmable ControlleratauProgrammable Binay system.

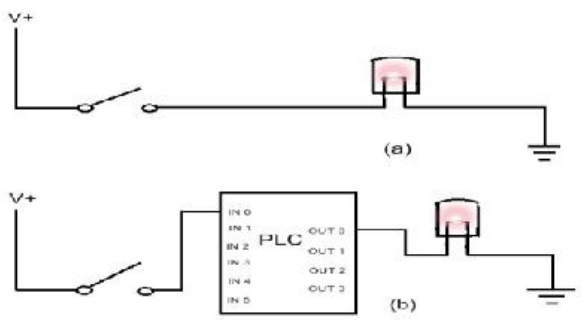

Gambar 1. (a) Rangkaian Saklar dan lampu secara hardwired dan (b) Menggunakan PLC (Adi, 2010)

\section{Motor Listrik}

Ada beberapa jenis motor listrik yaitu motor fasa terpisah (split- phase motor), motor kapasitor, motor universal dan motor kutub bayangan( shaded-pole motor). Tapi dalam penelitian ini digunakan Motor Listrik Universal 1 Fasa. Motor universal 1 Fasa adalah motor listrik yang bisa dialirkan dua jenis arus listrik yaitu arus AC ( alternating current) dan arus DC ( direct current) pada awalnya motor universal dirancang dan dibuat agar bisa memenuhi kebutuhan( Gunawan, 2013 ).

\section{Sistem Kontrol}

Diperlukan 3 rangkaian sistem kontrol pendukung yang harus di instal pada sistem kontrol PLCyaitu kontrol input pada daya yang mensuplai tegangan mengaktifkan PLC, Kontrol Proses pada PLC dan komputer dan kontrol sistem pada rangkaian output (Ogata,2011).

\section{Metode}

Penelitian dilakukan dengan menggunakan metode eksperimen perancangan program logika kontrol pada proses pembuatan roti yang di laksanakan di Laboratorium Instrumen dan Energi terbarukan jurusan Fisika FMIPA
UNSRAT Manado dari bulan Februari 2014 sampai Oktober 2014.

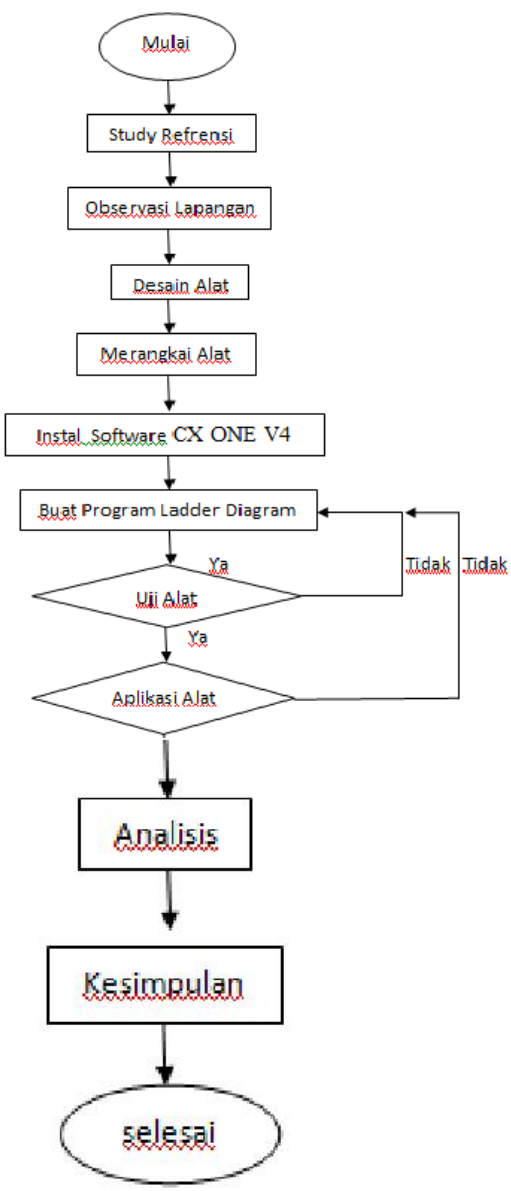

\section{Pembahasan Program ladder Diagram}

Penelitian perancangan Program Logika Kontrol pada proses pembuatan roti dengan mengalisis perbedaan waktu dan massa pada tahapan proses kerja $4-4,5 \mathrm{Kg}$ dengan $25 \mathrm{Kg}$. Berharap penelitian ini dapat bermanfaat untuk waktu proses kerja produksi lebih efisien, hasil Produk maksimal secara kualitas berdasarkan pedoman konsumen mengenai pangan dan keamanan pangan oleh pusat informasi produk industri makanan dan minuman, serta pembaruan teknologi sederhana yang mudah di pahami orang awam tanpa harus menyewa tenaga teknisi professional. 

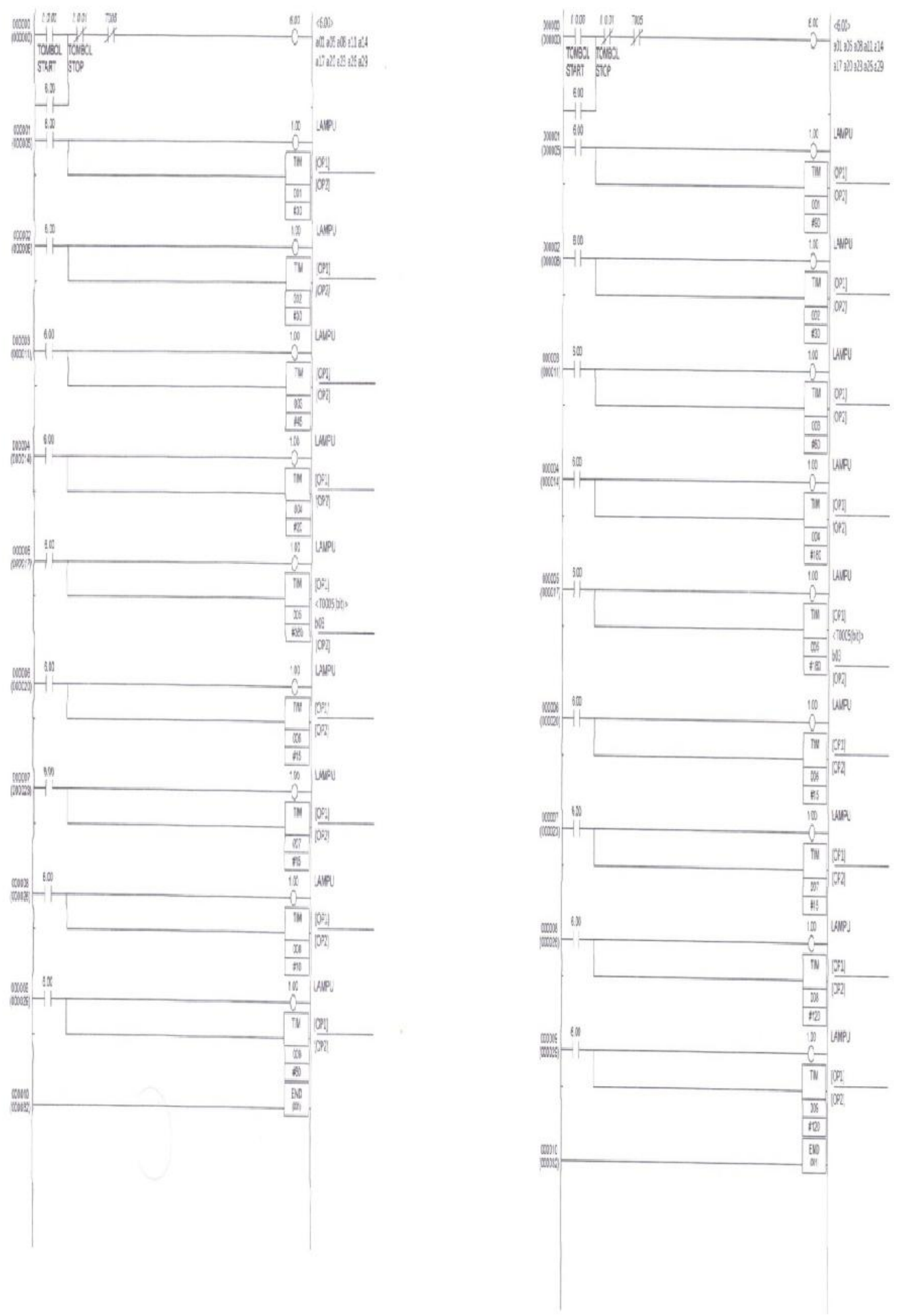

Gambar 2 Program Ladder Diagram Proses pembuatan Roti 4-4,5 kg

Gambar 3 Program Ladder Diagram Proses Pembuatan Roti $25 \mathrm{Kg}$ 


\section{Uji Pengontrolan Motor Listrik/ Lampu} Sirkuit

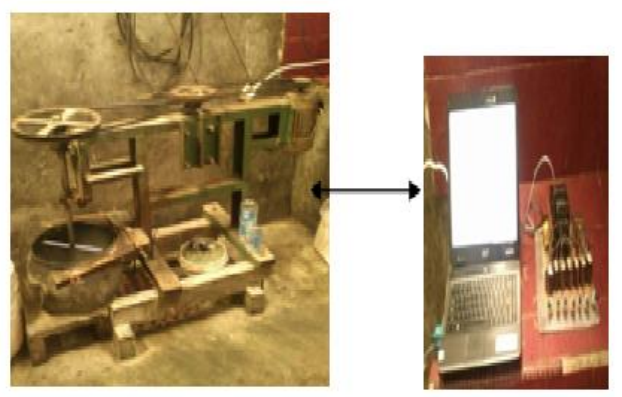

Gambar 4 Uji coba Keluaran pada motor listrik mixer roti sebagai output

Ketika MCB terhubung dengan arus listrik dan saklar mengalirkan arus listrik, mixer tidak akan berjalan sebelum mendapat perintah kerja dari komputer. program diagram ladder akan di jalankan melalui Komputer yang di perintahkan kepada PLC saat data berhasil di transfer. Perubah arus listrik menjadi energy mekanik pada motor berfungsi menggerakkan mixer Roti untuk mengolah adonan atas perintah dari komputer yang menjadi monitor pewaktuan lama pengadonan sebagai fungsi kerja awal dalam pengolahan Roti.

\section{KESIMPULAN}

Telah dirancang kontrol proses pembuatan roti menggunakan Programmable Logic Control (PLC). Proses kerja pada pembuatan roti dan Mengaplikasikan pada alat pendukung sistem kerja ketepatan waktu mempengaruhi hasil secara maksimal dan efisien. Menghasilkan produk olahan yang lebih baik serta sumber daya yang minimal.

\section{DAFTAR PUSTAKA}

Adi,N.Agung., 2010.Mekatronika. GRAHA Ilmu, Yogyakarta.

Ali,Muhammad.2014.Pembelajaran

Perancangan Sistem Kontrol PID dengan software Matlab. Jurnal Edukasi.1-8.

Gunawan,Indra.2013.Panduan Menggulung Ulang Kumparan Motor Listrik Satu Fasa.Andi, Yogyakarta.

Ogata,Katsuhiko. 2011.Teknik Kontrol Auto matik Jilid I, 2nd Edition, Penerbit Erlangga, Jakarta. 